\title{
OVERPRODUCTION AND PURIFICATION OF SOLUBLE RECOMBINANT HUMAN GRANULOCYTE COLONY STIMULATING FACTOR in Escherichia coli USING THIOREDOXIN AS FUSION
}

\author{
Dian Fitria Agustiyanti ${ }^{1,2}$, Debbie Sofie Retnoningrum ${ }^{1}$, \\ Heni Rachmawati ${ }^{1}$, and Asrul Muhamad Fuad ${ }^{2}$ \\ ${ }^{1}$ School of Pharmacy, Institut Teknologi Bandung, Jalan Ganesha 10, Bandung 40132, Indonesia; \\ ${ }^{2}$ Indonesian Institute of Sciences, Research Center for Biotechnology, Jalan Raya Bogor km 46, \\ Bogor, 16911, Indonesia
}

\begin{abstract}
Recombinant human Granulocyte Colony Stimulating Factor (G-CSF) has been produced in a soluble form in Escherichia coli BL21 (DE3) as a fusion protein. The open reading frame of G-CSF was synthetically constructed in previous work and was codon optimized for best expression in E. coli. In this research, the gene was fused to thioredoxin (Trx) at the N-terminal in pET32 vector. The purpose of this research was to optimize the overproduction and purification processes to obtain high yield recombinant protein in soluble form, and to characterize the Trx-G-CSF fusion protein. Overproduction was performed using IPTG induction method for 3 and 6 hours. The protein was purified by Ni-NTA affinity chromatography and separated using gradient concentration of imidazole. The purified protein was then characterized by SDS-PAGE and Western Blot analysis. Further, enterokinase was used to separate G-CSF from the fusion protein. The purified form of G-CSF was subsequently characterized using Western Blot and mass spectrometry using MALDI-TOF. The results showed that the fusion protein was successfully produced in soluble part as much as $48.25 \%$ were obtained after 3 hours of induction. The yield of fusion protein was $67.37 \%$ from total protein $(229.65 \mathrm{mg}$ protein/L culture). The Western Blot analysis showed the G-CSF band at around $18.6 \mathrm{kDa}$. Mass spectrometry with MALDI-TOF/ TOF revealed that $25.86 \%$ of amino acid residue was recognized as part of human G-CSF sequence.
\end{abstract}

Keywords: G-CSF, Thioredoxin, Soluble protein, E. coli

*Corresponding author :

Cibinong Science Center, Jl. Raya Bogor Km. 46, Cibinong 16911, Indonesia

Tel. +62-21-8754587, Fax. +62-21-87754588

Email: dian.fitria.agustiyanti@lipi.go.id

\section{Introduction}

Biopharmaceutical is a biotechnologically manufactured that has largely used to treat many diseases. Nevertheless, biopharmaceuticals are commonly protected by patents for a period of 20 years. This circumstance triggers the emergence of similar product socalled biosimilar. Filgrastim is a recombinant human granulocyte colony stimulating factor (rhG-CSF) produced by Amgen which was developed in 1980's. The rhG-CSF has been used as therapeutic protein for neutropenia and chemotherapy treatment in order to decrease the depression of white blood cell levels produced by cytotoxic agents (Welte et al., 1996). Biosimilar versions of filgrastim are now widely available and also used to induce peripheral blood stem cell (PBSC) mobilization in patients undergoing autologous stem cell transplantation (AHSCT) (Remenyi et al., 2014).

Meanwhile, hG-CSF is a central neutrophil-based immune defense due to its regulatory role in the growth, differentiation, survival, and activation of neutrophils and their precursors (Callard \& Gearing, 1994). hG-CSF is a single polypeptide chain protein that consists of 174 amino acids, five cysteines that form two intramolecular disulfide bridges between Cys36-Cys42 and Cys64-Cys74 and one free cysteine at residue 17 (Lu et al., 1989). hG-CSF crystal structure reveals fourhelix-bundle fold and has one O-linked glycosyl group at Thr133, which protects the protein from aggregation and does not 
influence the reseptor binding (Hill et al., 1993), therefore it is not required for its biological activity (Vanz et al., 2008). The non-glycosylated E. coli derived rhG-CSF is biologically active as it is when produced in mammalian cell lines (Bonig et al., 2001).

Currently, commercial rhG-CSF expressed in E. coli was produced in inclusion bodies (IB) form. The correct folding of protein which produced in $E$. coli was very important, often challenging due to the over expression protein could be lead to aggregation and formation of IB, especially when expressed in the cytoplasm (Khow et al., 2012). Expression of a protein in their soluble part is important for the protein to be biologically active. There are some properties of protein that can affect the formation of inclusion bodies such as presence of disulfide bonds (Lilie et al., 1998), post-translational modifications, hydrophobicity, net charge and secondary structure (Chiti et al., 2003). In order to recover soluble part from the IB, the proteins are solubilized in the presence of strong denaturants such as urea or guanidinium hydrochloride, followed by removing the denaturants under optimal conditions that assist refolding process (Lilie et al., 1998).

Many strategies are applied to improve protein solubility production in the cytoplasm. One of the strategies is expressed the protein as fusion protein, such as glutathione $\mathrm{S}$ transferase (GST), maltose binding protein (MBP) and thioredoxin (Trx). Trx is crucial proteins for oxidative stress defense, redox regulation of cellular function, and different metabolic pathway. Trx as thiol-dependent protein would mediate a reversible disulfide bond formation, this exchange reducing will take the equivalent between their active site cysteines and the cysteines of target proteins that will form the correct folding of the proteins (Ritz \& Beckwith, 2001). Trx overproduction to increase the solubility of foreign protein could effect redox reaction of disulfide linkages (Yasukawa et al., 1995). In this research, E. coli trx was used as a fusion partner to G-CSF protein in order to circumvent inclusion body formation in E. coli cytoplasm.

\section{Materials and Methods}

\section{Bacterial strain, vector and growth media}

Two E. coli strains were used in the experiment, DH5 $\alpha$ for sub cloning and plasmid amplification, and BL21(DE3) for protein expression. The pET32a $(+)$ vector (Novagen, Darmstadt, Germany) was linearized with $B g l I I$ enzyme (Fermentas, Vilnius, Lithuania). The G-CSFsyn ORF was previously constructed by dual asimetrical-overlap extension PCR and clone into pTZ57R vector (Fuad et al., 2013). Luria-Bertani (LB) broth and agar containing $50 \mu \mathrm{g} / \mathrm{ml}$ of ampicillin were used for growing recombinant $E$. coli and protein production.

\section{Plasmid Construction}

The G-CSF ORF contained BglII restriction sites obtained by PCR amplification from pTZ57R-G-CSF as DNA template. The DNA insert was separated by electrophoresis on $1 \%$ of agarose gel, then purified with DNA fragment extraction kit (Geneaid, Taipei, Taiwan). The DNA insert was inserted to pET$32 \mathrm{a}(+)$ vector at corresponding restriction sites, then transformed into E. coli DH5 $\alpha$. Analysis of transformant was performed by isolating the recombinant plasmid from single colony resistant to ampicillin on selection plate. The recombinant plasmid was analyzed using restriction with $B g l I I$ enzyme. For further analysis, DNA sequencing using $\mathrm{T} 7$ promoter and $\mathrm{T} 7$ terminator were used to confirm the DNA sequences. Template for DNA sequencing was produced by PCR amplification of recombinant plasmid using a pair of $\mathrm{T} 7$ promoter and $\mathrm{T} 7$ terminator primers. pET32(+)-G-CSF plasmid which was confirmed by DNA sequencing, subsequently transformed into E. coli BL21(DE3) cells.

\section{Protein Overproduction}

A single colony of E. coli BL21(DE3) harboring the pET32a(+)-G-CSF plasmid was inoculated into selective LB broth with agitation at $150 \mathrm{rpm}$ at $37^{\circ} \mathrm{C}$ overnight. Five percent $\mathrm{v} / \mathrm{v}$ of this overnight culture was inoculated into fresh selective LB broth with agitation at $150 \mathrm{rpm}$ at $37{ }^{\circ} \mathrm{C}$ until $\mathrm{OD}_{600} 0.6$ 0.8 was reached. The protein expression was induced by Isopropil- $\beta$-D-1-Thiogalactopyranoside (IPTG) with the final concentration of $0.4 \mathrm{mM}$. Cells were harvested 
after 3 hours by cold centrifugation at $4500 \times g$ for $15 \mathrm{~min}$.

\section{Protein Isolation, Purification and Cleavage}

Wet cell pellets were washed with phosphate buffer pH $7.4(20 \mathrm{mM}$ sodium phosphate and $0.5 \mathrm{M} \mathrm{NaCl}$ ) and recovered by cold centrifugation at $4500 \mathrm{xg}$ for $10 \mathrm{~min}$. The cells were resuspended in lysis buffer $(50 \mathrm{mM}$ Tris $\mathrm{HCl}$ at $\mathrm{pH} 7.4,3 \mathrm{mM}$ ethylenediaminetetraacetic acid (EDTA), $1 \mathrm{mM}$ phenylmethylsulfonyl fluoride (PMSF)) with ratio of $8 \mathrm{ml}$ lysis buffer per gram pellet. The cell suspension was frozen at $-20{ }^{\circ} \mathrm{C}$ for 15 $\mathrm{min}$, and then thawed at room temperature for $30 \mathrm{~min}$, this freeze-thaw process was repeated 10 times. The crude cell lysates were recovered by cold centrifugation at $9600 \mathrm{x} \mathrm{g}$ for $10 \mathrm{~min}$ at $4{ }^{\circ} \mathrm{C}$.

The Trx-G-CSF protein was produced as a fusion protein with histidine tag at its amino terminus and purified using Ni-NTA His-Bind Resin according to manufacturer's protocol (Qiagen, Hilden, Germany). Crude lysates were added to Ni-NTA agarose matrix at $1: 1$ $\mathrm{v} / \mathrm{v}$ ratio. The binding of protein was done using rotator at $4{ }^{\circ} \mathrm{C}$ for $18 \mathrm{~h}$. The matrix washed with washing buffer $(20 \mathrm{mM}$ imidazole in phosphate buffer $\mathrm{pH}$ 7.4) for five washing fraction and $50 \mathrm{mM}$ imidazole for another five washing fractions. The elution of bound protein was performed by using phosphate buffer consisting of gradient concentration of imidazole start from $50 \mathrm{mM}$ to $500 \mathrm{mM}$. Total and purified Trx-G-CSF fusion proteins was each analyzed using 15\% Sodium Dodecyl Sulphate Polyacrylamide Gel Electrophoresis (SDS-PAGE) and stained with coomassie blue.

Purified protein was dialyzed against 0.5 $\mathrm{M}$ Tris $\mathrm{HCl}$ of $\mathrm{pH} 8.0$ for $48 \mathrm{~h}$ with buffer changing every $6 \mathrm{~h}$. The fusion protein was then proteolytically cleaved with Enterokinase (EK) enzyme as described in manufacturer's protocol (EKMax, Invitrogen, California, USA). The protein was incubated with $\mathrm{EK}$ at $20{ }^{\circ} \mathrm{C}$ for $16 \mathrm{~h}$ using various amount of enzyme. Ni-NTA agarose affinity chromatography was used to separate G-CSF protein fragment from fusion. The cleavage product was analyzed with $17 \%$ SDS-PAGE.

\section{Western Blot Analysis}

The protein separated by $15 \%$ SDSPAGE was analyzed by Western blot analysis as described in protein blotting guide (Biorad). The acrylamide gel was transferred into nitrocellulose membrane. The protein on nitrocellulose membrane, incubated with primary antibody. The mouse anti-His monoclonal antibody (GE healthcare, Buckinghamshire, UK) was used as primary antibody for detection of Trx-G-CSF fusion protein or Trx-His tag fragment, diluted 1:3500 in TBS-T. The other was rabbit anti-GCSF polyclonal antibody (Santa Cruz Biotechnology, California, USA) used for detection of G-CSF protein after separation from Trx fusion, dilutes 1:3500 in TBS-T. Secondary antibody that used was goat antimouse IgG AP conjugate and goat anti rabbit IgG AP conjugate (Santa Cruz Biotechnology, California, USA) (1:3500) performed for each primary antibody. The signal was developed using Western Blue ${ }^{\circledR}$ substrate for AP (Promega, Wisconsin, USA).

\section{Protein analysis using MALDI-TOF/TOF MS}

MALDI-TOF spectrometry allows the identification of protein based on the amino acid sequence in polypeptide chains. Most typically, analyzed protein is processed enzymatically (e.g., by trypsin digestion), then selected peptides to undergo further fragmentation in spectrometer, and sizes $(\mathrm{m} / \mathrm{z}$ values) of fragmentary ions are determined in the so called tandem mass spectrometry (ms/ms) (Pietrowska and widlak, 2012).

Peptides were extracted according to standard techniques (Bringans, et.al., 2008), analyzed by MALDITOF-TOF (Matrix assisted laser desorption/ionization time of flight) mass spectrometer using a 41800 Proteomics Analyzer (AB Sciex). Spectra were analyzed to identify protein of interest using Mascot sequence matching software (Matrix Science) with Ludwig NR Database. This analysis was performed by Proteomic International Laboratory Ltd, Australia. 


\section{Results and Discussion}

\section{Construction of Recombinant Expression Vector}

The ORF was inserted downstream of DNA encoding for trxA and 6x-His-tag of pET-32a(+) at $B g l I I$ restriction site. DNA insert was of 567 base pairs (bp) in size, which correlated to the theoretical size of G-CSF ORF, 567 bp (Fig. 1, lane 1). After transformation, several putative recombinant plasmids were characterized by migration and single digestion analyses. Single digestion of a recombinant plasmid using EcoRI generated a linear plasmid of 6467 bp (Fig. 1, lane 3) which was in accordance with the theoretical size of recombinant pET-32a(+)-G-CSF.

The insert DNA of a recombinant plasmid was analyzed by DNA sequencing. The sequencing result showed that the insert DNA contained the sequence of codon-optimized ORF of G-CSF gene without any mutation. The confirmed recombinant plasmid was designated as pET-32a(+)-G-CSFsyn (Fig. 2).

\section{Overproduction, Purification and Characterization of Trx-hG-CSF Fusion Protein}

The expression of Trx-hG-CSF fusion protein was induced by addition of $0.4 \mathrm{mM}$ IPTG in LB liquid medium in a shake flask with vigorous shaking $(150 \mathrm{rpm})$ at $37^{\circ} \mathrm{C}$. The Trx-hG-CSF fusion protein was produced mostly in soluble form (96.6\%) and the remaining was as insoluble protein $(3.38 \%)$ (Fig. 3) . The calculation was using image $\mathrm{J}$ software. Results obtained by other research showed the rhG-CSF mostly in the form of Inclusion Body (IB) and to be solubilized in order to become an active protein (Fallah, et al., 2003, Vanz, et al., 2008, Babaeipour, et al., 2010, Dehaghani, et al., 2010, Rao, et al., 2008). hG-CSF codon optimization that was done to improve protein expression by reducing the GC content at 5 'end (Alrokayan, S., 2011) resulting rhG-CSF in soluble and insoluble form. Jeong and Lee, 2001, successfully expressed rhG-CSF on periplasmic space using fusion with Bacillus sp endoxylanase signal peptide. As previously reported by Song et al., 2009, rhG-CSF expressed with Pyr-B and GST as N-terminus fusion partner was effectively protected the protein from proteolysis and capable of increasing solubility. Native hG-CSF gene was difficult to be transcribed in E. coli because of the high $(\mathrm{G}+\mathrm{C})$ contents (Devlin et al., 1988). Therefore, in this research codon optimization was carried out to decrease $(\mathrm{G}+\mathrm{C})$ content of hG-CSF. Native hG-CSF had $65.7 \%$ of $(\mathrm{G}+$ C) content whereas rhG-CSF resulted in this research had $60.7 \%$ of $(G+C)$ content, respectively. rhG-CSF solubility was expected to increased significantly using $\mathrm{N}$-terminus Trx fusion and decreasing of $(\mathrm{G}+\mathrm{C})$ content. The result of Trx mechanism to helps fusion protein produced in soluble form was not clear. In oxidoreductase activity, Trx control the activity target protein via reversible thioldisulfide exchange reaction (Kumar, et al., 2003).

The crude intracellular proteins were obtained by cold sonication and freeze thaw methods. Protein obtained from freeze thaw method was better than that of sonication (Fig. 4). The appropriate isolation protein method can be selected based on the protein location. The E. coli Trx position was on the cytoplasmic facing the adhesion zones that exist between the inner and outer membranes of the E. coli cell envelope (Bayer, 1968). Since the Trx-hG-CSF fusion protein contained $6 x-H i s$ tag at its amino terminus, $\mathrm{Ni}-$ NTA affinity chromatography was applied to purify the protein of interest. The quality of protein purification was influenced by matrix binding capacity and quality of crude protein. The protein of interest found on flow through (FT) phase from sonication crude indicates that the protein unattached well on the matrix (Fig. 4b lane 4). The result also showed that the protein obtained from freeze thaw method was better than sonication method, there was no target protein band on FT phase indicating that protein is attached well on the matrix (Fig. 4a lane 4). The protein isolated using freeze thaw, would tear out the cell gently, and entirely separated by centrifugation.

The yield of purified Trx-hG-CSF fusion protein was approximately $228.5 \mathrm{mg}$ protein per L of cell culture (data were taken from 3 repetitions). The protein concentration was estimated by Image $\mathbf{J}$ software. The Image $\mathbf{J}$ software can determine concentration of a protein in SDS-PAGE gel bands. The protein of interest was applied in SDS-PAGE with some concentration of BSA as standard 
protein. A standard curve would be created by plotting intensity of BSA as a function of mass, then the concentration of protein interest can be defined (Ferreira and Rasband, 2012). SDS-PAGE analysis showed the presence of a protein band with the apparent size of $36 \mathrm{kDa}$ which was close to the theoritical size, 37.6 $\mathrm{kDa}$ (Fig. 4, lanes 6, 7, 8). The identity of the $36 \mathrm{kDa}$ protein was confirmed by a Western blot analysis using mouse monoclonal antibody against His-tag peptide (GE healthcare, Buckinghamshire, UK).

The fusion protein also contained enterokinase (EK) cleavage site (Fig. 1). The EK cleavage site was introduced into the sequence to separate the G-CSF protein from Trx fusion. Fig. 5A shows that the Trx-G-CSF fusion was cleaved specifically at EK cleavage site, resulting two protein fragments, a $19 \mathrm{kDa}$ product corresponding to the size of G-CSF and $17 \mathrm{kDa}$ product consisting of Trx and 6xHis-tag (Fig. 5, lane 2). Uncleaved protein fusion and the Trx portion were removed by Ni-NTA affinity chromatography, the G-CSF protein was recovered from the unbound fraction (Fig. 5, lane 3). Western blot analysis using rabbit polyclonal antibody against human G-CSF (Santacruz, Texas, USA) confirmed that the $19 \mathrm{kDa}$ product to be GCSF protein (Fig. 5B) and the $17 \mathrm{kDa}$ product was identified as Trx by mouse monoclonal antibody against His-tag (Fig. 5C).

MALDI-TOF/TOF analysis used trypsin in order to digest the recombinant protein. Trypsin is the most commonly used enzyme in mass spectrometry, it was used due to it highest specificity protease. Trypsin is a serine protease, it cleaves peptide chains mainly at the carboxyl side of the amino acids lysine or arginine, except when either is followed by proline (Rodriguez, et al., 2008) rhG-CSF characterization can be improved by using another protease, such as Chymotrypsin. In silico study using Chymotrypsin-high specificity to digest hG-CSF protein, showed 13 cleavage sites i.e. at position $20,25,43,72$, 91, 116, 118, 146, 151, 173, 177, 193, and 198. Chymotrypsin cleavage sites at amino acid 91, $116,118,146$, and 151 can digest the hG-CSF fragment which was can not be digested by trypsin enzyme.

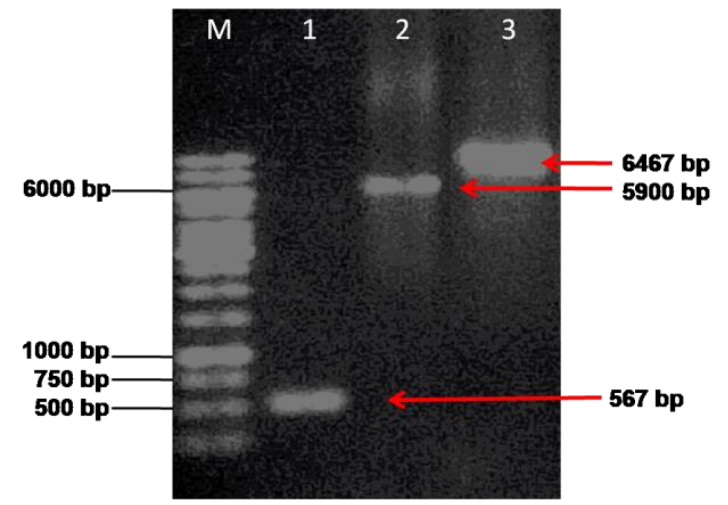

Fig. 1 Agarose gel electrophoresis of DNA. M. $1 \mathrm{~kb}$ DNA ladder, 1. ORF of CSFsyn gene, 2. Plasmid pET-32a(+) digested with BglII, 3 . Recombinant pET-32a(+)-CSFsyn digested with EcoRI

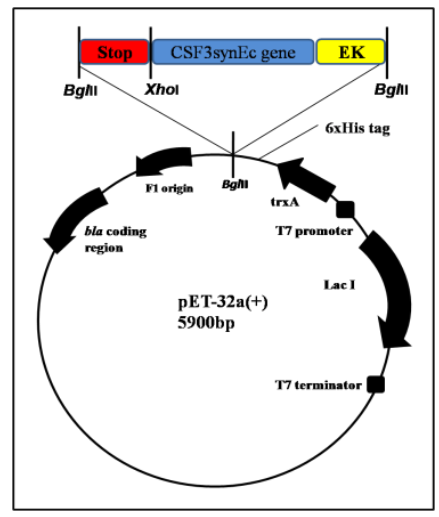

Fig. 2 Plasmid map of vector pET-32a(+)-GCSFsyn

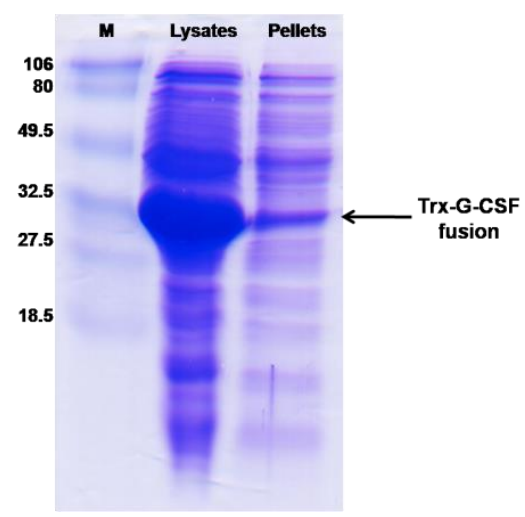

Fig. 3 SDS-PAGE analysis of overproduction of Trx-hG-CSF fusion protein in E. coli BL21(DE3). M. Marker 1. Soluble form in the protein lysate. 2. Insoluble form in cell pellet. 


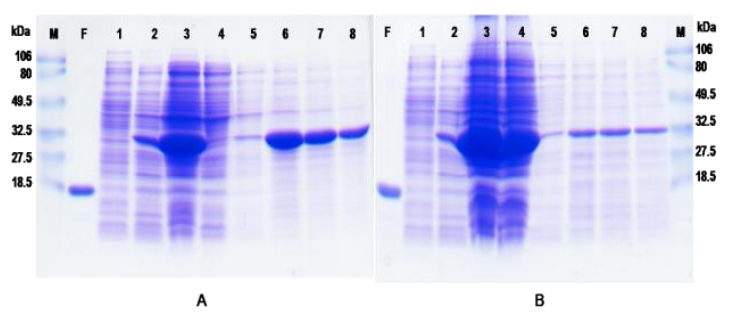

Fig. 4 Analysis of E. coli crude lysate and purified Trx-hG-CSF fusion protein using SDS-PAGE. Analysis of crude lysate obtained using freeze thaw method (a) and that obtained using sonication method (b). Lanes: 1. Crude lysate from non-recombinant E. coli, 2. Crude lysate from recombinant $E$. coli obtained from non-induced condition, 3. Crude lysate from recombinant $E$. coli from the induced condition, 4. Flow Trough fraction, 5. Washing fraction, 6 - 8. Eluted fraction, M. Unstained protein marker.

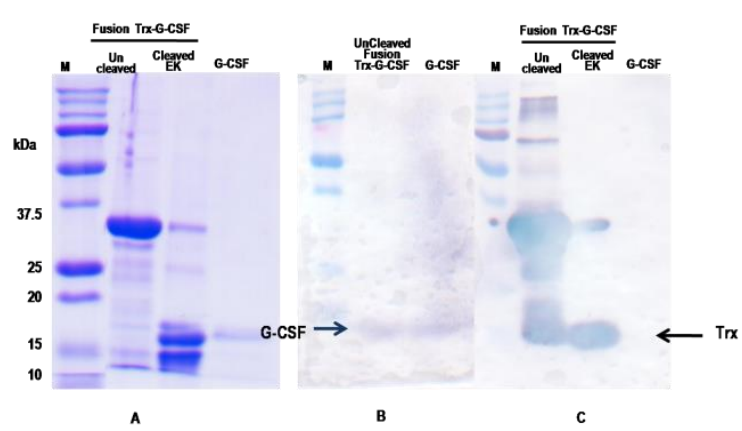

Fig. 5 Analysis of Trx-hG-CSF fusion protein cleavage by EK. (A) SDS-PAGE analysis of affinity-purified hG-CSF protein (B) Western blot analysis using rabbit polyclonal antibody against human hG-CSF, and (C) Western blot using mouse polyclonal antibody against 6xHis-tag.

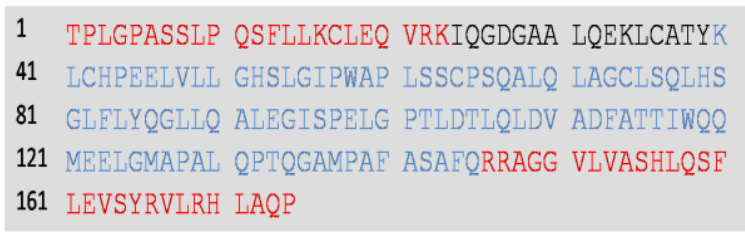

Fig. 6 Amino acid sequence of hG-CSF protein as determined by MALDI TOF/TOF MS analysis. Letters in red: amino acid residues identified in the analysis, letters in blue: 207 amino acid residues with no tryptic digestión site, letters in black: amino acid residues not identified in the analysis.

\section{Conclusion}

The Trx-G-CSF fusion protein was successfully produced as a soluble protein and confirmed by anti-His antibody. The G-CSF protein was obtained by EK digestion, followed by separation using affinity chromatography. The identity of G-CSF protein was confirmed by anti-G-CSF antibody and MALDI TOF/TOF analysis.

\section{Acknowledgements}

This research was supported by Indonesian Institute of Sciences (LIPI) Competitive Research Program, under The Post Genomic Molecular Farming sub-program in fiscal years 2012

\section{References}

Alrokayan, S.. (2011). Chemical Synthesis and Improved Expression of Recombinant human Granulocyte Colony Stimulating Factor cDna. Genetics and Molecular Research. 10 (4): 2671-2678, http://dx.doi. org/10.4238/2011.October.31.18.

Babaeipour, V., Abbas, M.P.H., Sahebnazar, Z., and Alizadeh, R.. (2010). Enhancement of human Granulocyte-Colony Stimulating Factor Production in Recombinant E. coli using Batch Cultivation. Bioprocess and Biosystems Engineering. 33: 591-598 http://dx.doi.org/10.1007/s00449-009-03803.

Bayer, M.E.. (1968). Areas of Adhesion Between Wall and Membrane of Escherichia coli Journal of General Microbiology. 53: 395404 http://dx.doi.org/10.1099/00221287-533-395.

Bonig, H.B. Hannen, M., lex, C., Wolfel, S., Banning, U., and Nurnberger, W.. (1999). Additive Effects of Infection and Neutropenia on The Induction of Granulocytopoietic Activity in vivo. Cancer.86 (2): 340-348.

Bringans, S., Eriksen, S., Kendrick, T.,Gopalakrishnakone, P., Livk, A., Lock, R., and Lipscombe, R.. (2008). Proteomic Analysis of the Venom of Heteronometrus longimanus (Asian Black Scorpion). 
Proteomics. 8: 1081-1095 http://dx.doi.org/ 10.1002/pmic.200700948.

Callard, R. E. and A. J. H. Gearing. (1994). The Cytokine Facts Book. Academic Press, Inc., San Diego, California.

Chiti, F., Stefani, M., Taddei, N., Ramponi, G., and Dobson, C.M... (2003). Rationalization of the effects of mutations on peptide and protein aggregation rates. Nature. 424: 805 808.

Dehaghani, S.A., Babaeipour, V., mofid, M.R., Divsalar, A., and Faraji, F.. (2010). An Efficient Purification Method for High Recovery of Recombinant human Granulocyte Colony Stimulating Factor from Recombinant E. coli. International Journal of Environmental Science and Development. 1(2): 111-114.

Devlin, P.E., Drummond, R.J., Toy, P., Mark, D.F., Watt, K.W., and Devlin, J.J.. (1998). Alteration of Amino-Terminal Codons of human Granulocyte Colony-Stimulating Factor Increases Expression Levels and Allows Efficient Processing by Methionine Aminopeptidase in Escherichia coli. Gene. 65: 13-22.

Fallah, M.J., Akbari, B., Saeedinia, A.R., Karimi, M., Vaez, M., Zeinoddini, M., Soleimani, and M., Maghsoudi, N.. (2003). Overexpression of Recombinant human Granulocyte Colony-Stimulating Factor in $E$. coli. International Journal of Molecular Sciences. 28 (3): 131-134.

Ferreira, T., and Rasband, W., (2012), Image J User Guide IJ 1.46r. Nature Methods Issued. http://imagej.nih.gov/ij/docs/guide/userguide .pdf.

Fuad, A. M., Yuliawati, and Agustiyanti, D.F.. (2013). Desain dan konstruksi gen CSF3 Sintetik (CSF3syn) mengandung kodon preferensi Escherichia coli dengan teknik PCR.Proceeding of national seminar XXII "Kimia dalam Industri dan Lingkungan". 87-98. ISSN : 0854-4778

Hill, C.P., Osslund, T.D., and Eisenberg, D.. (1993).The Structure of Granulocyte Colony Stimulating Factor and It's Relationship to Other Growth Factor. Proceeding of National Academy of Science, USA. 90: 5167-5171.
Jeong, K.J. and Lee, S.Y.. (2001) Secretory Production of human Granulocyte ColonyStimulating Factor in Escherichia coli Protein expression and purification. 23: 311318. http://dx.doi.org/10.1006/prep.2001. 1508.

Johnson, B.H. and Hecht, M.H.. (1994). Recombinant Protein can be Isolated from $E$. coli by Repeated Cycles of Freezing and Thawing. Biotechnology. 12: 1357-1360, http://dx.doi.org/10.1038/nbt1294-1357.

Khow, O. and Suntrarachun, S.. (2012). Strategies for Production of Active Eukaryotic Proteins in Bacterial Expression System. Asian pasific journal of tropical biomedicine 159 162. http://dx.doi.org/10.1016/S2221-1691 (11) 60213-X.

Kumar, J.K., Tabor, S., and Richardson, C.C.. (2003). Proteomic Analysis of ThioredoxinTargeted Proteins in Escherichia coli. The National Academy of Sciences of the USA. http://dx.doi.org/10.1073/pnas.0308701101.

Lilie, H., E. Schawrz, R. and Rudolph. (1998). Advances in Refolding of Proteins Produced in E. coli. Current Opinion in Biotechnology. 9: 497-501.

Lu, S., Boone, T., Souza, L., and Lai, P.. (1989). Disulfide and Secondary Structure of Recombinant human Granulocyte ColonyStimulating Factor. Archives of Biochemistry and Biophysics. 1: 81-92.

Pietrowska, M., and Widlak, P.. (2012). MALDIMS-Based Profiling of Serum Proteome : Detection of Changes Related to Progression of Cancer and Response to Anticancer Treatment. International Journal of Proteomics, volume 2012, ID 926427. http://dx.doi.org/10.1155/2012/926427

Rao, D.V.K., Narasu, M.L., and Rao, A.K.S.B.. (2008). A Purification Method for Improving the Process Yield and Quality ofRecombinant human Granulocyte ColonyStimulating Factor Expressed in Escherichia coli and It's Characterization. Biotechnologyand Applied Biochemistry.50: 77-87. http://dx.doi.org/101.1042/BA200701 30.

Remenyi, P., Gopcsa, L., Marton, I., Reti, M., Mikala, G., Peto, M., Barta, A., Batai, A., Farkas, Z., Borbenyi, Z., Csukly, Z., Bodo, I., Fabian, J., Kiraly, A. And Lengyel, L., (2014), Peripheral Blood Stem Cell 
Mobilization and Engraftment After Autologous Stem Cell Transplantation with Biosimilar rhG-CSF. Advances in Theraphy, 31 (4) : 451-460. http://dx.doi.org/10.1007/ s12325-014-0114.

Ritz, D. and beckwith, J.. (2001). Roles of ThiolRedox Pathways in Bacteria.Annual Review of Microbiology. 55: 21-48. http://dx.doi.org/ 10.1146/annurev.micro55.1.21.

Rodriguez, J., Gupta, Nisin., Smith, Richard D., Pevzner, Pavel A.. (2008). Does Trypsin cut Before Proline?. Journal of Proteome Research. 7 (1) : 300 - 305. http://dx.doi.org/ $10.1021 / \mathrm{pr} 0705035$.

Song, J.A., Han, K.Y., Ahn, K.Y., Park, J.S., Seo, H.S., and Lee, J.. (2009). Proteolysis and Synthetic Strategy of Human G-CSF in Escherichia coli BL21(DE3). Enzyme and Microbial Technology. 45: 7-14. http://dx.doi.org/10.1016/j.enzmictec.2009.0 2.010 .

Vanz, A. LS., Gaby R., Mario S.P., Jocelei M.C., Sergio L. D., Luiz A. B., and Diego S. S.. (2008). Human Granulocyte Colony Stimulating Factor (hG-CSF) : Cloning, Overexpression, Purification \& Characterization. Microbial Cell Factories. 7 - 13. http://dx.doi.org/10.1186/1475-2859-713

Welte, K., Gabriel, J., Bronchud, M.H., Platzer, E., and Morstyn, G.. (1996). Filgrastim (r-metHuG-CSF) : The First 10 years. Blood.88: $1907-1929$.

Yasukawa, T., C. Kanei-Ishii, T. Maekawa, J. Fujimoto, T. Yamamoto and S. Ishii. (1995). Increase of Solubility of Foreign Proteins in Escherichia coli by Coproduction of Bacterial Thioredoxin. The Journal of Biological Chemistry. 270: 25328-25331. 